REVIEW

\title{
Mobile Learning in Medical Education: Review
}

\author{
Kieran Walsh ${ }^{1}$
}

\section{ABSTRACT}

In the past several years, mobile learning made rapid inroads into the provision of medical education. There are significant advantages associated with mobile learning. These include high access, low cost, more situated and contextual learning, convenience for the learner, continuous communication and interaction between learner and tutor and between learner and other learners, and the ability to selfassess themselves while learning. Like any other form of medical pedagogy, mobile learning has its downsides. Disadvantages of mobile learning include: inadequate technology, a risk of distraction from learning by using a device that can be used for multiple purposes, and the potential for breakdown in barriers between personal usage of the mobile device and professional or educational use. Despite these caveats, there is no question but that mobile learning offers much potential. In the future, it is likely that the strategy of mobile first, whereby providers of e-learning think of the user experience on a mobile first, will result in learners who increasingly expect that all e-learning provision will work seamlessly on a mobile device.

KEYWORS: Medical education, mobile learning, technology

DOI:http://dx.doi.org/10.4314/ejhs.v25i4.10

\section{Mobile Learning}

Only a few years ago, a paper on mobile learning would have focussed on the uses of a laptop personal computer (1). However, the pace of change in this area of technology means that many students will now not know even what a personal digital assistant is (2). In the recent past, elearning designers created e-learning content for use on a desktop first and foremost, and subsequently thought about whether or how best to redesign the content for a mobile device. Today, many e-learning designers have developed a mobile first strategy-whereby they create content with a mobile device in mind in the first instance. Indeed, the pace of change has been so transformational that there is now debate as to what constitutes a mobile device or indeed what constitutes mobile learning. If all e-learning can be done on a mobile device, then, perhaps the specific terminology "mobile learning" should be abandoned altogether. Certainly, mobile learning can range from a formal registered approach to self-learning guided via the free e-courses which are designed in an andragogic way. The purpose of this article is to cover the wide range of resources provided by mobile learning-both formal and informal, and free and paid-for (3). It is also important to remember that learning is fundamentally a process and that mobile technology simply facilitates that process. In this era of rapid change, it is worth pausing and taking stock of the various advantages and disadvantages that are associated with mobile learning. In this short article, I outline these advantages and disadvantages and suggest methods to fully exploit the advantages and minimize the disadvantages.

The main advantage of mobile learning is simply its access (4). Mobile devices can enable students to learn in any time or location-however and wherever it suits them (5). Students can learn at home or when commuting if they so wish. Often they can learn when they have nothing else to do (when they can dedicate their undivided attention to relevant educational outcomes). These are

${ }^{1}$ BMJ Learning, BMJ Publishing Group, London

Corresponding Author: Kieran Walsh, email: kmwalsh@bmjgroup.com 
environments that many educationalists could not have dreamt of a number of years ago-a library of resources available at the learner's discretion and in a physical environment where often they have to be-for example when travelling to college. Software applications (Apps) now enable the access of content when the user is off-line. Learning can now happen everywhere. Access to resources is a fundamental first step in learning, and mobile learning enables a step change in this access.

A second advantage associated with mobile learning is cost. As with any form of e-learning, there is the cost of hardware and software, the cost of faculty and learner time, and the cost of the physical learning environment (for example the computer aided learning room) (6 7). There is also the cost of the connectivity charge. For many of these components of the overall costs, the cost of mobile learning is no different from that of elearning. However, mobile learning enables the educator to strike through certain aspects of the budget. Many students already have mobile phones or tablets, and many of these are already equipped with the necessary software. For students who do not have mobile devices, these can be purchased at low cost and at especially low cost when the purchase is made in bulk -for example, for a class of say 200 students. The cost of the physical environment is simply not necessary with mobile learning. Medical education is expensive and so savings that can be made by these means will be significant (89).

Another added value associated with mobile learning is that it enables more situated and contextual learning. This is both integral to the learning and to the technology enabled by mobile devices. For example, a student or postgraduate trainee may have an unanswered questions when on the ward. Mobile access will enable them to answer that question there and then and indeed to put their learning into action there and then-and sometimes to the benefit of patients. Such learning may take seconds, but it is actionable learning and it may be better embedded than learning that takes place in the lecture hall or the library.

A fourth advantage is that mobile learning can enable the learner to do other activities while learning. Therefore, lectures can be recorded and made available via podcasting. These in turn may be listened too by means of live streaming, or users can download them and listen on an unconnected device. This enables learners to do whatever they like and still listen; they can drive, go to the gym or do housework. Once again, it is an example of technology that puts the learner in control (10 11).

Mobile devices can also be used to enable quick, easy and continuous communication and interaction between learner and tutor and between learner and other learners (12). This can happen inside the lecture hall with students answering questions online by means of Google surveys or twittering the content of the lectures to those who did not attend. It can also happen outside of the lecture hall with tutors communicating tasks to small or large groups of learners by means of their mobile devices and then learners collaborating amongst themselves to complete the tasks as a team.

Much medical education on mobile devices is taken up with assessment. Here, it seems that there is a good match between the educational format and the technology. In the format of closed response assessment, a small amount of information can fit on a small screen with a question at the end. The learners can click on the answer that they think is correct and arrive immediately at the correct answer on the next screen. Software applications (Apps) can enable banks of questions to be made available when off line. The provision is also often a good fit with learner behaviours-learners do not often wish to spend hours doing thousands of assessment questions-rather they often like doing small chunks of learning by assessment at a time, being able to monitor their progress towards achieving competence (13).

Of course, mobile learning is not a panacea; like any other form of medical pedagogy, it has its downsides. One disadvantage of mobile learning is that it is completely reliant on technology and sometimes that technology is inadequate or fails. This can be related to hardware-with insufficient battery life or inadequate screen size (14 15). It can be related to presence and speed of connectivity. Memory may be limited or the software on the device may only support a limited number of file formats. As with most technology barriers, all these are being slowly overcome. Batteries have longer lives, internet speeds get 
faster, and the capacity for memory storage ever larger.

However, the pedagogical challenges may prove to be more difficult to overcome. It is clear that learning becomes easier by facilitation from technology. However, there remain significant pedagogical challenges. There is a risk of distraction from learning by using a device that can be used for multiple purposes, and there is a risk of distraction from the constantly changing environments in which mobile devices are used (16). The advantage of availability can become a disadvantage if pursued too far. Thus, the constant opportunity for learning may mean that some students will never take a break, or will take their learning home with them to the detriment of their personal and family lives. High users of online learning will often have a healthy approach to this use; however, some availability may generate overuse or unhealthy use (17). There is also the potential for breakdown in barriers between personal usage of the mobile device and professional or educational use. For example, what policies should medical schools have regarding allowing their students to use medical school tablets to access personal email or watch films or communicate with their peers by means of social networks (18)? Should they ban this and if so would such a ban be reasonable? Or should they have any policy at all? These potential dilemmas should be thought through before medical education institutions move too quickly into mobile accessible curricula. There is also a risk that educators will become seduced by the technology and forget about the learning. However, it must never be forgotten that the aims and objectives of the learning should guide the methods of learning. The concept and content of learning is more important than any new technology. It should also not be underestimated that for mobile learning to become useful, there has to be a teacher, a content creator, a supervisor, an online facilitator, in other words, a human resource at the other end. Lastly, any new technology will only work if the end-user can access it. In this regard, there may be a role for simple devices that can run on limited networks. (19 20)

Despite these caveats, there is no question but that mobile learning offers much potential. People are always learning, whether formally or informally, and mobile technology helps this process. In the future, it is likely that the strategy of mobile first, whereby providers of e-learning think of the user experience on a mobile first, will result in learners who increasingly expect that all e-learning provision will work seamlessly on a mobile. The issue of what constitutes mobile learning will also likely become less controversial as e-learning providers work towards deviceresponsive design where any learning content will work on any device in any place and at any time.

\section{REFERENCES}

1. Chatterley T and Chojecki D. Personal digital assistant usage among undergraduate medical students: exploring trends, barriers, and the advent of smartphones. Journal of the Medical Library Association, 2010;98:157-160.

2. Prensky M. Digital natives, digital immigrants. On the Horizon, 2001;9:1-6.

3. Ally, M. (2009). Mobile learning: Transforming the delivery of education and training. Edmonton, AB: Athabasca University Press.

4. Boruff JT, Storie D. Mobile devices in medicine: a survey of how medical students, residents, and faculty use smartphones and other mobile devices to find information. $J$ Med Libr Assoc, 2014;102(1):22-30.

5. Ellaway RH, Fink P, Graves L, Campbell A. Left to their own devices: medical learners' use of mobile technologies. Med Teach, 2014;36(2):130-8.

6. Sandars J. Cost-effective e-learning in medical education. In: Walsh $\mathrm{K}$ (Ed). Cost effectiveness in medical education. Radcliffe: Abingdon, 2010: PP. 40-47.

7. Ker J, Hogg G, Maran N. Cost effective simulation. In: Walsh K (Ed). Cost effectiveness in medical education. Radcliffe: Abingdon, 2010:61-71

8. Walsh K, Jaye P. Cost and value in medical education. Educ Prim Care, 2013; 24(6):3913.

9. Walsh K, Rutherford A, Richardson J, Moore P. NICE medical education modules: an analysis of cost-effectiveness. Educ Prim Care, 2010; 21(6):396-398.

10. Ford, M., \& Leinonen , T. (2009). MobilED mobile tools and services platform for formal and informal learning. In M. Ally (Ed.) 
Mobile learning: Transforming the delivery of education and training (pp. 195-214). Edmonton, AB: Athabasca University Press.

11. Wellman, S. (2007). Google lays out its mobile user experience strategy (11 April). Retrieved from http://www.informationweek.com/blog/main/a rchives/2007/04/google_lays_out.html (accessed 15.4.15)

12. Sclafani J, Tirrell TF, Franko OI. Mobile tablet use among academic physicians and trainees. J Med Syst, 2013;37(1):9903.

13. Schuwirth LWT and van der Vleuten CPM. Programmatic assessment: from assessment of learning to assessment for learning. Medical Teacher, 2011;33 (6), 478-85.

14. Maniar N, Bennett E, Hand S, Allan G. The effect of mobile phone screen size on video based learning. Journal of Software, 2008; 3(4): 51-61.

15. Elias T. Universal Instructional Design Principles for Mobile Learning. International Review of Research in Open and Distance Learning. 2011; 12 (2).

16. Crescente ML, Lee D. Critical issues of mlearning: design models, adoption processes, and future trends. Journal of the Chinese
Institute of Industrial Engineers, 2011;28(2): 111-123.

17. Sandars J, Walsh K, Homer M. High users of online continuing medical education: A questionnaire survey of choice and approach to learning. Medical Teach, 2010; 32: 83-85

18. Thompson LA, Dawson K, Ferdig R, Black EW, Boyer J, Coutts J, Black NP. The intersection of online social networking with medical professionalism. J Gen Intern Med, 2008; 23: 954-957.

19. Trifonova, A., \& Ronchetti, M. (2003). Where is mobile learning going?. In: A. Rossett (Ed.), Proceedings of World Conference on ELearning in Corporate, Government, Healthcare, and Higher Education, pp. 17941801. Chesapeake, VA: AACE.

20. Gregson, J., \& Jordaan, D. (2009). Exploring the challenges and opportunities of m-learning within an international distance education programme. In: M. Ally (Ed.) Mobile learning: Transforming the delivery of education and training (pp. 215-246). Edmonton, AB: Athabasca University Press. 